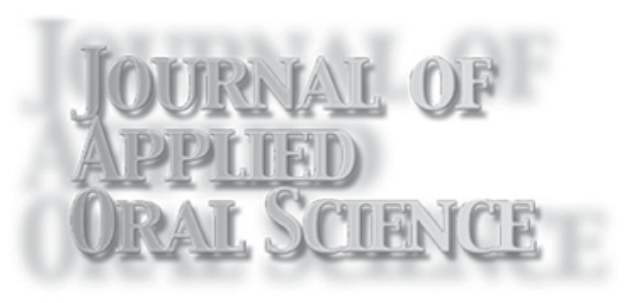

ISSN 1678-7757

\title{
Editorial
}

\section{The Journal of Applied Oral Science has been selected to be indexed and included in MEDLINE}

Dear Readers and Reviewers,

We could not have better news to share with all of you! We are pleased to inform you that the Journal of Applied Oral Science (JAOS) has been selected to be indexed and included in MEDLINE. Citations from articles indexed, the indexing terms, and the English abstracts printed in the JAOS, starting from the first issue of 2008, will be included and searchable using PubMed. Additionally, links will be included for the free full texts available at http:// www.scielo.br/jaos. Undoubtedly, this accomplishment will be instrumental to increase the journal's international visibility, our main goal.

The indexation of the JAOS in MEDLINE, ISI Web of Knowledge (SCIE $\left.{ }^{\mathrm{TM}}\right)$, SciELO and SCOPUS, among other important databases, confirms our commitment to hard and serious work as well as respect for all the authors who submit their manuscripts for possible publication in the JAOS. We are aware that our responsibility is even greater now, but we face this moment with high motivation. We understand we are moving towards the right direction since the standards of distinguished international databases have been reached by the $\boldsymbol{J A O S}$.

Such outstanding achievements were only possible due to the belief of authors and reviewers in our journal. I am also extremely grateful to my devoted team, the librarians Valéria Cristina Trindade Ferraz and José Roberto Plácido Amadei, the secretary Sônia Cláudia Pirola Rodrigues, the journalist Neimar Vitor Pavarini, and the cover and picture designer Rubens Kazuo Kato. Without the loyalty and patience of these five extremely competent professionals, my ideas and plans for the improvement of the JAOS would have never become a reality.

At this moment, it is my obligation to thank Professor Suely Vilela, the President of the University of São Paulo, Professor Luiz Fernando Pegoraro, Dean of the Bauru
School of Dentistry, the National Council for Scientific and Technological Development (CNPq) and the Foundation for the Coordination of Higher Education and Graduate Training (CAPES) for the financial support for the print version of the JAOS. I must also emphasize all the institutional support I have been receiving from the faculty members of the Bauru School of Dentistry, mostly by their contribution as reviewers.

In the current issue of the JAOS, besides the excellent 11 full papers from distinguished contributors, we proudly publish the abstracts of works selected for presentation at the $21^{\text {st }}$ Academic Conference of the Bauru School of Dentistry "Professor Flavio Fava de Moraes and Professor Aymar Pavarini". The Scientific Coordinator and President were Professor José Alberto de Souza Freitas and the senior undergraduate student Gabriela Letícia Natalício, respectively. This conference was held on May 14-17, 2008. Approximately 1,000 undergraduate and graduate students, clinicians as well as speakers attended this important event, and many of them showed their scientific and clinical works during oral and poster presentations. Therefore, you are also invited to read the selected abstracts. We hope you enjoy this issue!

Please, feel free to contact us through our e-mail address: jaos@usp.br. We also invite all readers, contributors and reviewers to visit our free complete online collection and our online submission system at http://www.scielo.br/jaos.

Finally, I take advantage of this editorial to wish all of you a Merry Christmas and a Happy 2009!

Yours sincerely,

Carlos F. Santos, DDS, MSc, PhD, Associate Professor Editor-in-Chief Journal of Applied Oral Science 